\title{
Electromigration에 의한 $\mathrm{Sn}-0.7 \mathrm{Cu}$ 솔더 금속간화합물 성장 예측
}

\author{
허민혁 ${ }^{1,3} \cdot$ 강남현 $^{1,2, *} \cdot$ 박성훈 $^{3} \cdot$ 김준기 $^{4} \cdot$ 홍원식 $^{5}$ \\ ${ }^{1}{ }^{ㅂ ㅜ ㅅ ㅏ ㄴ ㄷ ㅐ ㅎ ㅏ ㄱ ㄱ ㅛ ~ ㅊ ㅏ ㅅ ㅔ ㄷ ㅐ ㅈ ㅓ ㄴ ㅈ ㅏ ㄱ ㅣ ㅍ ㅏ ㄴ ㅎ ㅚ ㄹ ㅗ ㅎ ㅏ ㄱ ㄱ ㅘ ~}$ \\ ${ }^{2}$ 부산대학교 재료공학과 \\ ${ }^{3}$ 부산대학교 기계공학부 \\ 4한국생산기술연구원 용접접합그룹/마이크로조이닝센터 \\ ${ }^{5}$ 전자부품연구원 융복합전자소재연구센터
}

\section{Kinetics of Intermetallic Compounds Growth Induced by Electromigration of Sn-0.7Cu Solder}

\author{
Min-Hyeok Heo ${ }^{1,3}$, Namhyun Kang ${ }^{1,2, *}$, Seonghun Park ${ }^{3}$, Jun-Ki Kim ${ }^{4}$, and Won Sik Hong ${ }^{5}$ \\ ${ }^{I}$ Education Program for SAMSUNG Advanced Integrated Circuit, Pusan National University, Busan 46241, \\ Republic of Korea \\ ${ }^{2}$ Department of Materials Science \& Engineering, Pusan National University, Busan 46241, Republic of Korea \\ ${ }^{3}$ Department of Mechanical Engineering, Pusan National University, Busan 46241, Republic of Korea \\ ${ }^{4}$ Welding \& Joining R\&D Group/Micro-Joining Center, Korea Institute of Industrial Technology, Incheon 21999, \\ Republic of Korea \\ ${ }^{5}$ Electronic Convergence Materials \& Device Research Center, Korea Electronics Technology Institute,
} Gyeonggi-do 13509, Republic of Korea

\begin{abstract}
The reliability of printed circuit boards (PCB) has emerged as a critical concern as the size of solder bump decreases and current density to solder bump increases by fine pitch formation. The main failure mode of solder bumps is open-circuits due to void formation as intermetallic compounds (IMC) grow, mainly due to electromigration. This study modeled IMC growth by electromigration in $\mathrm{Sn}-0.7 \mathrm{Cu}$ solder bumps. The IMC produced in the reflow process grew again significantly due to electromigration upon application of electric current. The thickness of the IMC under electromigration increased as the current increased from $1 \mathrm{~A}$ (current density: $1.3 \times 10^{4} \mathrm{~A} / \mathrm{cm}^{2}$ ) to $1.5 \mathrm{~A}$ (current density: $1.9 \times 10^{4} \mathrm{~A} / \mathrm{cm}^{2}$ ). For the current density applied in the study, IMC growth of $\mathrm{Cu}_{6} \mathrm{Sn}_{5}$ was faster than that of $\mathrm{Cu}_{3} \mathrm{Sn}$. The Nernst-Einstein relation was used to model the IMC growth induced by electromigration. The modeling results of $\mathrm{Cu}_{3} \mathrm{Sn}$ and $\mathrm{Cu}_{6} \mathrm{Sn}_{5}$ thickness showed good agreement with the experimental observations of IMC growth under electromigration. Specifically, a good prediction for $\mathrm{Cu}_{3} \mathrm{Sn}$ growth was derived for the current density of $1.3 \times 10^{4} \mathrm{~A} / \mathrm{cm}^{2}$. However, the modeling values of $1.9 \times 10^{4} \mathrm{~A} / \mathrm{cm}^{2}$ and $\mathrm{Cu}_{6} \mathrm{Sn}_{5}$ thickness showed a minor difference as compared with the experimental IMC thickness results. As the current density increased from $1.3 \times 10^{4} \mathrm{~A} / \mathrm{cm}^{2}$ to $1.9 \times 10^{4} \mathrm{~A} / \mathrm{cm}^{2}$, the solder bump probably evolved under heat generation, and the further effects of aging and thermomigration should be incorporated in the IMC growth.
\end{abstract}

(Received April 7, 2016; Accepted June 17, 2016)

Keywords: electromigration, $\mathrm{Sn}-0.7 \mathrm{Cu}$ solder, intermetallic compounds, current density, modeling

\section{1. 서 론}

최근 모바일·전자제품 시장에서 스마트폰, 3D TV, 테블릿 컴퓨터와 같은 제품은 소형화 및 고성능화에 대한 요구가 크 게 증가하고 있다. 이와 같은 요구를 만족시키기 위하여 칩

*Corresponding Author: Namhyun Kang

[Tel: +82-51-510-3027, E-mail: nhkang@pusan.ac.kr]

Copyright (c) The Korean Institute of Metals and Materials (chip)과 메인 보드(main board)를 전기적으로 연결시켜주는 인쇄 전자회로 기판(printed circuit board, $\mathrm{PCB}$ ) 기판 내에 더 많은 소자 및 단자를 실장할 수 있는 미세피치(pitch) 구현 기 술 개발이 반드시 필요하다 [1]. 미세피치 기술이 개발되면서 $\mathrm{PCB}$ 기판의 하나인 플립칩 볼 그리드 어레이(flip chip ball grid array, $\mathrm{FCB}$ )에서 칩과 기판(substrate)를 전기적으로 연 결시켜주는 솔더범프(solder bump)의 크기가 작아지고, 솔더 


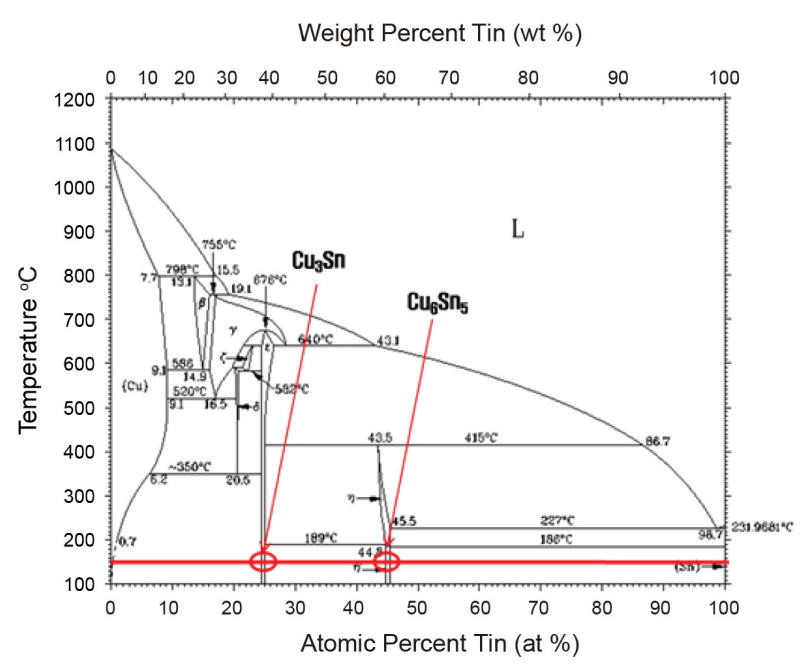

Fig. 1. Phase diagram of $\mathrm{Cu}-\mathrm{Sn}$ alloys [22].

범프에 인가되는 전류밀도는 급격히 증가하고 있다. 이로 인 해 솔더범프에 electromigration(금속 배선에 인가된 전류로 인해 금속원자가 전자의 이동방향으로 이동하는 현상)이나 Joule 열에 의한 솔더범프 온도 증가로 2 차상 형성 등을 일으 키게 된다. 이와 같은 현상들에 의해 패키지(package)에서 전 기적 단선이나 전기저항이 급격히 증가하여 단전되는 개방 회로 파괴(open-circuit failure)와 같은 심각한 문제가 발생한 다 [2-5]. 특히, open-circuit failure의 주 원인으로 알려진 솔 더와 기판 사이에 형성되는 2 차상인 금속간화합물 (intermetallic compound, IMC)과 커켄달기공(Kirkendall void)의 형성 및 성장은 electromigration의 영향에 의해 가속 화된다고 알려져 있다. 기존 연구에서 electromigration은 온 도 $150{ }^{\circ} \mathrm{C}$, 전류밀도 $8 \times 10^{3} \mathrm{~A} / \mathrm{cm}^{2}$ 에서 수 백시간 이내에 발 생한다고 보고된다 [6]. 미래의 전자장치에서 솔더범프는 50 $\mu \mathrm{m}$ 의 직경을 가지게 되면서 각 솔더범프에 인가되는 전류는 일반적으로 0.2-0.4 A가 인가되며, 이 때의 전류밀도는 약 $10^{4} \mathrm{~A} / \mathrm{cm}^{2}$ 에 도달하게 된다 [7].

$\mathrm{IMC}$ 와 Kirkendall void의 성장은 밀접한 관계를 가지고 있 다. $\mathrm{IMC}$ 가 성장하면서 $\mathrm{Cu}-\mathrm{Sn}$ 의 $\mathrm{IMC}^{\mathrm{O}}$ 닌 $\mathrm{Cu}_{3} \mathrm{Sn}, \mathrm{Cu}_{6} \mathrm{Sn}_{5}$ 와 구 리 $(\mathrm{Cu})$ 패드 $(\mathrm{Pad})$ 와의 계면에서 Kirkendall void가 발생한다. 가공이 발생하는 이유는 각 상에서 $\mathrm{Cu}$ 와 $\mathrm{Sn}$ 원자의 확산 유 속 차이 때문이며, $\mathrm{Cu}$ 패드에서 구리 원자의 이동으로 구리 원자가 소모되어 Kirkendall void가 발생한다고 알려져 있다 [8,9]. 이로 인해 여러 가지 합금의 솔더범프에서 electromigration 현상에 의한 IMC 및 Kirkendall void 성장에 관한 연구가 활발히 진행되고 있다. 그리고 패키지가 작동 시
기판과 칩 사이의 온도구배가 생기면서 발생하는 thermomigration 현상도 IMC 성장 요인 중 하나로 연구되고 있다. Thermomigration은 전류 인가 시 패키지 내의 칩과 기 판 사이에 Joule 열 효과에 의해 발생한다. 상대적으로 온도 가 높은 칩에서 온도가 낮은 기판으로 온도구배가 존재하고, 이로 인하여 원자가 열적 스트레스(stress)를 해소하기 위해 이동하는 현상을 말한다 $[10,11]$. 그러나 thermomigration은 일정한 온도구배 조건에서 electromigration 효과에 비해 $\mathrm{IMC}$ 성장에 지배적인 요인으로 생각할 수 없다는 연구보고 가 있다 [12].

지금까지 무연솔더로 주로 사용되는 $\mathrm{Sn}-\mathrm{Ag}$ 계 합금의 솔더 범프는 IMC 거동과 예측 및 수명평가에 대한 연구가 많이 진 행되었다 [13-17]. 최근 관심이 늘고 있는 $\mathrm{Sn}-0.7 \mathrm{Cu}$ 솔더는 $\mathrm{Sn}-\mathrm{Ag}$ 합금에 비해 크립(creep) 강도가 낮아서 피로모드 (failure mode)에서 솔더의 변형이 쉽게 일어나기 때문에, 전 자패키지에서 칩과 기판 사이의 열팽창계수 차이에 의해 발 생하는 평탄도(warpage) 불량 시 솔더가 변형되어 오히려 크 랙(crack)에 대한 저항성은 우수하다고 알려져 있어 최근 사 용이 증가하고 있다 [18]. 그러나 아직 IMC 성장 및 예측에 관한 연구가 미흡한 실정으로, $\mathrm{Sn}-0.7 \mathrm{Cu}$ 솔더에서 electromigration에 의한 금속간화합물과 Kirkendall void 성 장에 의한 단락을 예측하기에 어려움이 있다. 따라서 본 연구 는 $\mathrm{Sn}-0.7 \mathrm{Cu}$ 솔더에서 electromigration에 의한 $\mathrm{Sn}-\mathrm{Cu}$ 의 IMC 의 성장 거동을 실험적으로 관찰하고 성장 거동을 예측할 수 있는 모델링 결과와 비교하였다.

\section{2. 금속간화합물 성장 모델링}

\section{1 경계 조건 설정}

$\mathrm{Sn}-0.7 \mathrm{Cu}$ 솔더의 경우 리플로우(reflow) 공정이 진행되는 온도는 $25-242{ }^{\circ} \mathrm{C}$ 의 온도구간이므로, 솔더범프의 주석이 열 확산에 의해 $\mathrm{Cu}$ 패드로 침입하고 상호확산(interdiffusion)을 통하여 $\mathrm{IMC}$ 가 생성된다. 이 $\mathrm{IMC}$ 는 그림 1 의 $\mathrm{Cu}-\mathrm{Sn}$ 상태도 에서 확인할 수 있듯이 $\mathrm{Cu}_{3} \mathrm{Sn}(\varepsilon)$ 과 $\mathrm{Cu}_{6} \mathrm{Sn}_{5}(\eta)$ 의 $\mathrm{IMC}$ 로 구성 한다 [19]. 그리고 상태도를 통해 각각의 IMC가 존재하는 원 자 분율을 보면 $150{ }^{\circ} \mathrm{C}$ 에서 $\mathrm{Cu}_{3} \mathrm{Sn}(\varepsilon)$ 은 $\mathrm{Cu}$ 원자 $75 \mathrm{at} \%$ 와 $\mathrm{Sn}$ 원자 $25 \mathrm{at} \%$ 로 구성되어 있으며, $\mathrm{Cu}_{6} \mathrm{Sn}_{5}\left(\eta^{\prime}\right)$ 는 $\mathrm{Cu}$ 원자 54.5 $\mathrm{at} \%$ 와 $\mathrm{Sn}$ 원자 $45.5 \mathrm{at} \%$ 로 구성되어 있다 [20]. $\mathrm{Cu}_{6} \mathrm{Sn}_{5}$ 와 $\mathrm{Cu}_{3} \mathrm{Sn}$ 사이의 계면에서 두 상의 상호 확산에 의해 각 상의 성 장이 진행된다. 주석원자는 $\mathrm{Cu}_{6} \mathrm{Sn}_{5}$ 에서 $\mathrm{Cu}_{3} \mathrm{Sn}$ 으로 이동하 고, $\mathrm{Cu}$ 원자는 $\mathrm{Cu}_{3} \mathrm{Sn}$ 에서 $\mathrm{Cu}_{6} \mathrm{Sn}_{5}$ 으로 이동한다. 그러나 
Table 1. Boundary conditions for $\mathrm{Cu}-\mathrm{Sn}$ binary alloys at $150{ }^{\circ} \mathrm{C}$ [23].

\begin{tabular}{c|cccccc}
\hline Phase & $\mathrm{Cu}$ & $\mathrm{Cu}_{3} \mathrm{Sn}^{+}$ & $\mathrm{Cu}_{3} \mathrm{Sn}^{-}$ & $\mathrm{Cu}_{6} \mathrm{Sn}_{5}{ }^{+}$ & $\mathrm{Cu}_{6} \mathrm{Sn}_{5}{ }^{-}$ & $\mathrm{Sn}$ \\
\hline $\begin{array}{l}\text { Atomic } \\
\text { fraction }\end{array}$ & 0.993 & 0.765 & 0.755 & 0.549 & 0.541 & 0.007 \\
\hline
\end{tabular}

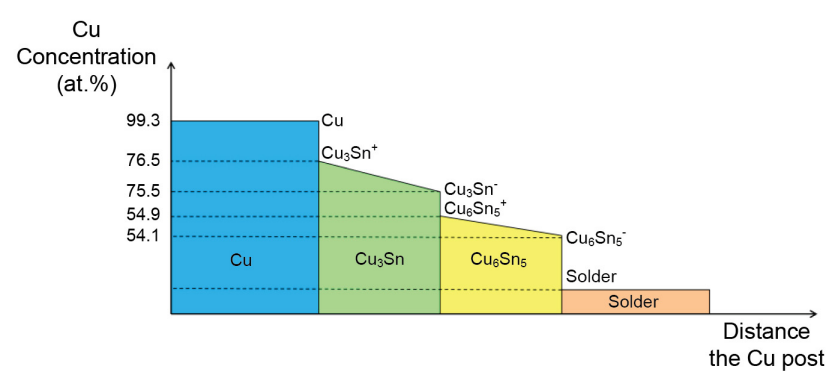

Fig. 2. Atomic fraction gradient between $\mathrm{Cu}$ and solder

electromigration의 영향 하에서 $\mathrm{Cu}$ 와 $\mathrm{Sn}$ 원자는 전자와 같은 방향으로 이동하게 되면서, 언더 범프 금속 피복(under bump metallizaton, $\mathrm{UBM})$ 의 $\mathrm{Cu}$ 원자는 $\mathrm{Cu}_{3} \mathrm{Sn}, \mathrm{Cu}_{6} \mathrm{Sn}_{5}$ 및 솔더범프 내부로 확산하여 각 $\mathrm{IMC}$ 의 성장을 가속화시킨다.

이와 같은 성장 메커니즘에 기초하여 각 $\mathrm{IMC}$ 는 일정한 원 자 분율을 가지는 것을 알 수 있으며, 그림 1 의 $\mathrm{Cu}-\mathrm{Sn}$ 상태도 에서 추출한 각 $\mathrm{IMC}$ 의 원자 분율을 경계조건으로 설정할 수 있다. 전자기기가 작동할 때의 온도는 $80-150{ }^{\circ} \mathrm{C}$ 로 알려져 있 어, $\mathrm{IMC}$ 가 가장 빠르게 성장할 수 있는 $150{ }^{\circ} \mathrm{C}$ 에서 각 상의 원자 분율을 경계조건으로 설정하였다 [21].

그림 2는 각 상의 $\mathrm{Cu}$ 원자 분율 구배를 도식화하였다. 그림 1 의 $\mathrm{Cu}-\mathrm{Sn}$ 상태도를 보면 $150{ }^{\circ} \mathrm{C}$ 에서 각 $\mathrm{IMC}$ 의 구리원자는 $\mathrm{Cu}_{3} \mathrm{Sn}$ 에서 75.5-76.5 at $\%, \mathrm{Cu}_{6} \mathrm{Sn}_{5}$ 에서 54.1-54.9 at $\%$ 를 가진 다. 이는 솔더 접합부 경계에서 생성되는 각 $\mathrm{IMC}$ 에서 $\mathrm{Cu}$ 패 드에서 멀어질수록 $\mathrm{Cu}$ 의 원자분율은 적어진다고 생각할 수 있다. 따라서 $\mathrm{Cu}$ 패드와 $\mathrm{Cu}_{3} \mathrm{Sn}$ 이 접하는 지점의 $\mathrm{Cu}$ 원자분율 을 각각 $\mathrm{Cu}$ 와 $\mathrm{Cu}_{3} \mathrm{Sn}^{+}, \mathrm{Cu}_{3} \mathrm{Sn}$ 과 $\mathrm{Cu}_{6} \mathrm{Sn}_{5}$ 가 접하는 지점을 각각 $\mathrm{Cu}_{3} \mathrm{Sn}^{-}$와 $\mathrm{Cu}_{6} \mathrm{Sn}_{5}{ }^{+}, \mathrm{Cu}_{6} \mathrm{Sn}_{5}$ 와 솔더가 접하는 지점을 $\mathrm{Cu}_{6} \mathrm{Sn}_{5}{ }^{-}$로 설정하였다. 정확한 경계조건은 표 1 에 나타내었다.

\subsection{Electromigration 성장속도 모델}

Electromigration에 의한 유속은 Nernst-Einstein 식 [24]을 사용하여 다음과 같이 나타낸다.

$$
J=C v=C \mu F=C\left(\frac{D}{k T}\right) Z^{*} e p j
$$

$\mathrm{J}$ 는 유속, $\mathrm{C}$ 는 단위부피당 원자의 수(원자의 농도), $\mathrm{v}$ 는 속 도, $\mu$ 는 이동도, $\mathrm{F}$ 는 전자의 운동량 전이에 의한 구동력, $\mathrm{D}$ 는 확산계수, $\mathrm{k}$ 는 Boltzmann 상수, $\mathrm{T}$ 는 절대온도, $\mathrm{Z}$ *는 유효전 하수(effective charge number), e는 전하량, $\rho$ 는 비저항, 그리 고 $\mathrm{j}$ 는 전류밀도이다.

식 (1)을 사용하여 eletromigration에 의한 금속간화합물 유속을 나타내면 다음과 같다.

$$
J_{I M C}=J_{C u}+J_{s n}=C_{C u} \frac{D_{C u}}{k T} Z_{c u}^{*} e p j+C_{S n} \frac{D_{S n}}{k T} Z_{s n}^{*} e p j
$$

이때 원자의 농도는 다음과 같이 표현할 수 있다.

$$
C_{C u}=C_{0} n_{C u} \quad C_{S h}=C_{0} n_{S n}
$$

$\mathrm{C}_{\mathrm{Cu}}$ 는 단위부피당 $\mathrm{Cu}$ 원자의 수, $\mathrm{C}_{\mathrm{Sn}}$ 은 단위부피당 $\mathrm{Sn}$ 원 자의 수, $\mathrm{C}_{0}$ 는 원자의 밀도, $\mathrm{n}_{\mathrm{Cu}}$ 는 $\mathrm{Cu}$ 원자의 분율, $\mathrm{n}_{\mathrm{Sn}}$ 은 $\mathrm{Sn}$ 원 자의 분율이다.

$\mathrm{Sn}-\mathrm{Cu}$ 계 $\mathrm{IMC}$ 는 모두 $\mathrm{Cu}$ 와 $\mathrm{Sn}$ 으로만 이루어져 있으므로,

$$
\begin{aligned}
& n_{I M C}=n_{C u}+n_{S n}=1 \\
& C_{I M C}=C_{C u}+C_{S n}=C_{0} n_{C u}+C_{0} n_{S n}
\end{aligned}
$$

으로 표현할 수 있으며, 각 상에서 $\mathrm{Cu}$ 와 $\mathrm{Sn}$ 의 원자분율은 식 (4)와 (5)를 만족해야 한다.

식 (3)을 식 (2)에 대입하면 다음과 같이 전개된다.

$$
\begin{aligned}
J_{I M C} & =C_{0} n_{C u} \frac{D_{C u}}{k T} Z^{*}{ }_{C u} e p j+C_{0} n_{S n} \frac{D_{S n}}{k T} Z_{S h}^{*} e p j \\
& =C_{0}\left(n_{C u} \frac{D_{C u}}{k T} Z_{C u}^{*}+n_{S h} \frac{D_{S n}}{k T} Z_{S n}^{*}\right) e p j
\end{aligned}
$$

그림 1 과 표 1 에서 볼 수 있듯이 각 $\mathrm{IMC}$ 가 형성되는 원자 분율에서 $\mathrm{Cu}$ 와 $\mathrm{Cu}_{3} \mathrm{Sn}, \mathrm{Cu}_{3} \mathrm{Sn}$ 과 $\mathrm{Cu}_{6} \mathrm{Sn}_{5}, \mathrm{Cu}_{6} \mathrm{Sn}_{5}$ 와 솔더범프 의 계면에서의 원자 분율은 큰 차이를 보인다. 이러한 원자 분율의 차이가 각 $\mathrm{IMC}$ 사이의 $\mathrm{Cu}$ 및 $\mathrm{Sn}$ 원자의 유속에도 영 향을 주기 때문에, 각 상 계면에서의 원자분율 차이를 식 (6) 에 대입하여, electromigration에 의한 IMC의 유속을 식 (7)과 (8)로 전개하였다. 


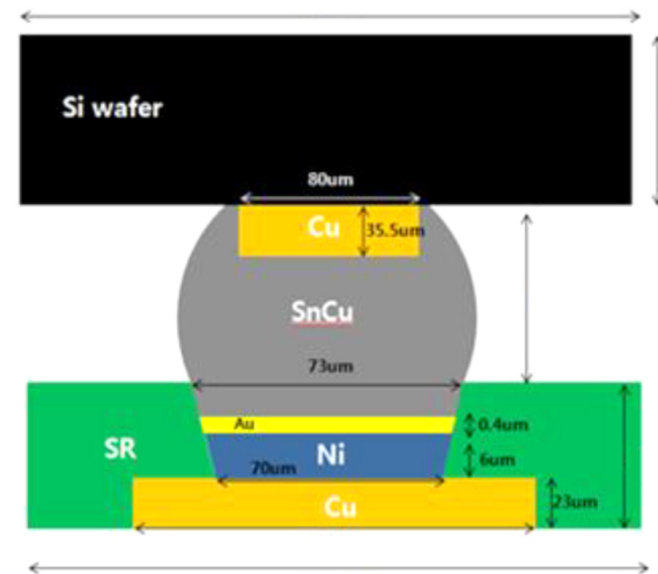

Fig. 3. Schematic diagram of solder joint and $\mathrm{Cu}$ post assembly

$$
\begin{aligned}
& \mathrm{J}_{\mathrm{EM}, \mathrm{Cu} \mathrm{u}_{3} \mathrm{Sn}}=C_{0, C u_{3} S n}\left(\frac{\left(\mathrm{n}_{1, \mathrm{Cu}}-\mathrm{n}_{2, \mathrm{Cu}}\right) \mathrm{D}_{1, \mathrm{Cu}}}{\mathrm{kT}} \mathrm{e} \rho \mathrm{j} \mathrm{Z}_{1, \mathrm{Cu}}^{*}+\frac{\left(\mathrm{n}_{2, \mathrm{Sn}}-\mathrm{n}_{1, \mathrm{Sn}}\right) \mathrm{D}_{1, \mathrm{Sn}}}{\mathrm{kT}} \mathrm{e} \mathrm{j} \mathrm{Z}_{1, \mathrm{Sn}}^{*}\right) \\
& +C_{0, C u_{3} S n}\left(\frac{\left(\mathrm{n}_{3, \mathrm{Cu}}-\mathrm{n}_{4, \mathrm{Cu}}\right) \mathrm{D}_{2, \mathrm{Cu}}}{\mathrm{kT}} \operatorname{e\rho jZ_{2,\mathrm {Cu}}^{*}}+\frac{\left(\mathrm{n}_{4, \mathrm{Sn}}-\mathrm{n}_{3, \mathrm{Sn}}\right) \mathrm{D}_{2, \mathrm{Sn}}}{\mathrm{kT}} \mathrm{e} \mathrm{j} \mathrm{Z}_{2, \mathrm{Sn}}^{*}\right)
\end{aligned}
$$

$$
\begin{array}{r}
\mathrm{JEM}, \mathrm{Cu}_{6} \mathrm{Sn}_{5}=C_{0, C u_{6} \mathrm{Sn}_{5}}\left(\frac{\left(\mathrm{n}_{3, \mathrm{Cu}}-\mathrm{n}_{4, \mathrm{Cu}}\right) \mathrm{D}_{3, \mathrm{Cu}}}{\mathrm{kT}} \mathrm{e} \rho \mathrm{j} \mathrm{Z}_{3, \mathrm{Cu}}^{*}+\frac{\left(\mathrm{n}_{4, \mathrm{Sn}}-\mathrm{n}_{3, \mathrm{Sn}}\right) \mathrm{D}_{3, \mathrm{Sn}}}{\mathrm{kT}} \mathrm{e} \rho \mathrm{j} \mathrm{Z}_{3, \mathrm{Sn}}^{*}\right) \\
+C_{0, C u_{6} S n_{5}}\left(\frac{\left(\mathrm{n}_{5, \mathrm{Cu}}-\mathrm{n}_{6, \mathrm{Cu}}\right) \mathrm{D}_{4, \mathrm{Cu}}}{\mathrm{kT}} \mathrm{e} \mathrm{j} \mathrm{Z}_{4, \mathrm{Cu}}^{*}+\frac{\left(\mathrm{n}_{6, \mathrm{Sn}}-\mathrm{n}_{5, \mathrm{Sn}}\right) \mathrm{D}_{4, \mathrm{Sn}}}{\mathrm{kT}} \mathrm{e}_{\mathrm{T}} \mathrm{jZ}_{4, \mathrm{Sn}}^{*}\right)
\end{array}
$$

$\mathrm{n}_{1, \mathrm{i}}$ 는 $\mathrm{Cu}$ 와 $\mathrm{Cu}_{3} \mathrm{Sn}$ 과의 계면에서 $\mathrm{Cu}$ 상에 존재하는 $\mathrm{i}$ 원자의 원자 분율, $\mathrm{n}_{2, \mathrm{i}}$ 는 $\mathrm{Cu}$ 와 $\mathrm{Cu}_{3} \mathrm{Sn}$ 과의 계면에서 $\mathrm{Cu}_{3} \mathrm{Sn}$ 상에 존재 하는 $\mathrm{i}$ 원자의 원자 분율, $\mathrm{n}_{3, \mathrm{i}}$ 는 $\mathrm{Cu}_{3} \mathrm{Sn}_{\text {과 }} \mathrm{Cu}_{6} \mathrm{Sn}_{5}$ 의 계면에서 $\mathrm{Cu}_{3} \mathrm{Sn}$ 상에 존재하는 $\mathrm{i}$ 원자의 원자 분율, $\mathrm{n}_{4, i}$ 는 $\mathrm{Cu}_{3} \mathrm{Sn}$ 과 $\mathrm{Cu}_{6} \mathrm{Sn}_{5}$ 와의 계면에서 $\mathrm{Cu}_{6} \mathrm{Sn}_{5}$ 상에 존재하는 $\mathrm{i}$ 원자의 원자 분 율, $\mathrm{n}_{5, \mathrm{i}}$ 는 $\mathrm{Cu}_{6} \mathrm{Sn}_{5}$ 과 솔더의 계면에서 $\mathrm{Cu}_{6} \mathrm{Sn}_{5}$ 상에 존재하는 $\mathrm{i}$ 원자의 원자 분율, $\mathrm{n}_{6, i}$ 는 $\mathrm{Cu}_{6} \mathrm{Sn}_{5}$ 와 솔더의 계면에서 솔더에 존재하는 i원자의 원자 분율이다.

\section{Electromigration 실험 방법}

\subsection{Electromigration 시편 제작 및 실험 조건}

기판과 실리콘 웨이퍼(Si wafer)에서 전류가 이동하는 통 로인 회로는 직렬 연결 방식으로 구성하였으며, 웨이퍼와 기 판을 연결시켜주는 솔더 접합부의 구조는 그림 3에 나타내었 다. 솔더범프의 직경은 $100 \mu \mathrm{m}$, 기판은 니켈-침지금도금 (electroless nickel-immersion gold, ENIG) 표면처리, 웨이퍼

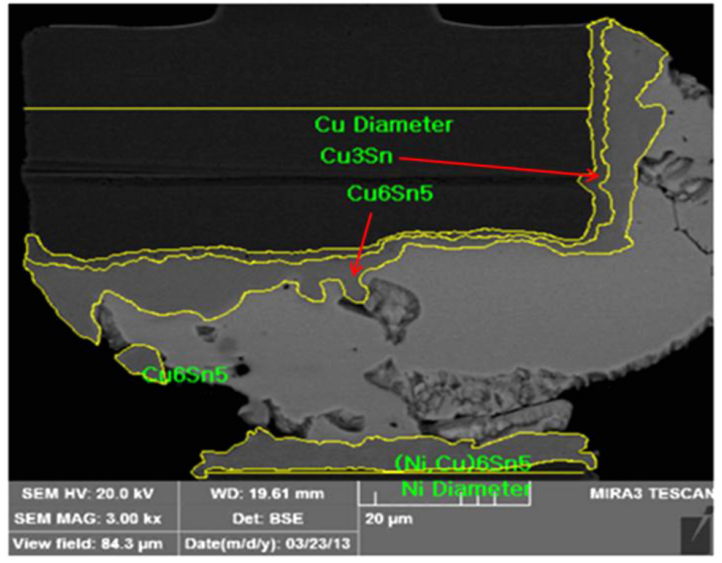

Fig. 4. IMC area measurement to calculate IMC thickness

에는 $\mathrm{Cu}$ 패드를 도금하여 제작하였고, 전자의 흐름은 웨이퍼 에서 기판으로 이동하게 설계하였다. 실제 솔더 접합부 제작 시 미세한 솔더의 크기로 인해 솔더가 한쪽으로 치우치는 웨 이퍼와 기판 간의 부정렬이 발생하더라도, 솔더가 $\mathrm{Cu}$ 패드의 윗면 전체를 덮고 있으면 양품으로 판단하였다. 이는 직진성 을 가지는 전류의 특성으로 인해 솔더가 $\mathrm{Cu}$ 패드 윗면 전체 를 덮고 있으면 전자의 이동으로 인한 IMC 성장 경향을 모사 하는 데는 큰 영향이 없기 때문이다. 따라서 electromigration 에 의한 $\mathrm{Cu}-\mathrm{Sn} \mathrm{IMC}$ 의 관찰은 웨이퍼 쪽에서 수행하였다. 전 류밀도는 $1.3 \times 10^{4} \mathrm{~A} / \mathrm{cm}^{2}$ 와 $1.9 \times 10^{4} \mathrm{~A} / \mathrm{cm}^{2}$ 의 조건으로 실 험을 진행하였다. 모든 전류 인가 실험은 실제 패키지 구동조 건 모사를 위하여 $150{ }^{\circ} \mathrm{C}$ 의 로(furnace)에서 수행하였다.

\section{$3.2 \mathrm{IMC}$ 두께 측정}

$\mathrm{IMC}$ 의 성장 거동 관찰은 주사전자현미경(field emission scanning electron microscope, FE-SEM, HITACHI S-4800) 을 사용하였다. 그리고 솔더범프 내 IMC의 명확한 상 구분을 위해 주사전자현미경의 후방산란전자(back scattering electron, BSE) 모드와 전자탐침미세분석기(electron micro probe analyzer, EPMA, JEOL JXA-8100)를 사용하였다. $\mathrm{IMC}$ 가 차지하는 넓이는 주사전자현미경과 전자탐침미량분 석기 사진을 이미지 분석 프로그램으로 그림 4 와 같이 측정 하였고, 이를 다시 $\mathrm{Cu}$ 패드의 직경을 나누어 $\mathrm{IMC}$ 의 두께를 측정하였다 [25]. 그림 4의 위쪽은 웨이퍼와 솔더범프의 경계 로써, 전류 인가 시 $\mathrm{Cu}_{3} \mathrm{Sn}$ 과 $\mathrm{Cu}_{6} \mathrm{Sn}_{5} \mathrm{IMC}$ 가 성장하였다. 아래 쪽은 기판과 솔더범프의 경계로서 $(\mathrm{Ni}, \mathrm{Cu})_{6} \mathrm{Sn}_{5} \mathrm{IMC}$ 가 성장 하였다. 전자의 흐름은 그림 4의 위쪽에서 아래쪽으로 이동 하므로, electromigration에 의한 IMC의 성장 거동은 위쪽 계 

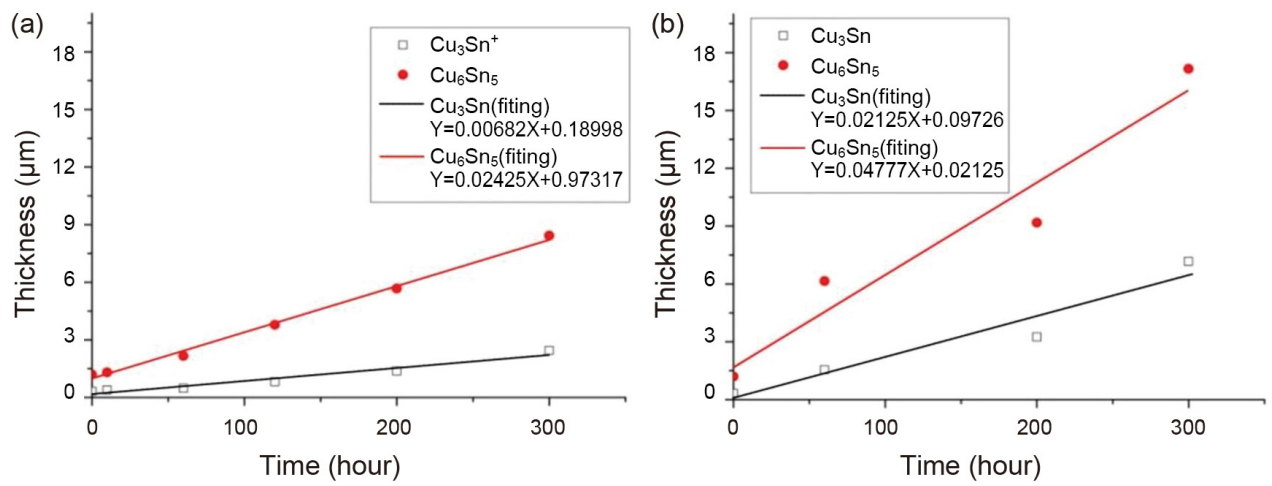

Fig. 5. IMC thickness for applying (a) $1 \mathrm{~A}-1.3 \times 10^{4} \mathrm{~A} / \mathrm{cm}^{2}$ and (b) $1.5-1.9 \times 10^{4} \mathrm{~A} / \mathrm{cm}^{2}$.

면에서 발생하는 $\mathrm{Cu}_{3} \mathrm{Sn}$ 과 $\mathrm{Cu}_{6} \mathrm{Sn}_{5} \mathrm{IMC}$ 를 관찰하였다.

\section{4. 결과 및 고찰}

전류밀도 및 전류 인가 시간에 따른 $\mathrm{IMC}$ 의 두께 실험결과 그림 $5 \mathrm{a}$ 는 $1.3 \times 10^{4} \mathrm{~A} / \mathrm{cm}^{2}$ 의 전류밀도가 인가되어 있을 때 0-300시간 동안 솔더범프 경계면에서 성장하는 IMC 두께를 측정한 결과이다. $\mathrm{Cu}_{3} \mathrm{Sn}$ 금속간화합물의 두께는 electromigration 시험 전 $0.33 \mu \mathrm{m}$ 에서 300시간 후 $2.45 \mu \mathrm{m}$ 로 증가하였다. 또한 $\mathrm{Cu}_{6} \mathrm{Sn}_{5} \mathrm{IMC}$ 의 두께는 electromigration 시 험 전 $1.20 \mu \mathrm{m}$ 에서 300 시간 후 $8.43 \mu \mathrm{m}$ 로 증가하였다. 이로 인해 $\mathrm{Cu}_{3} \mathrm{Sn}, \mathrm{Cu}_{6} \mathrm{Sn}_{5}$ 는 각각 시간이 지남에 따라 성장하였다. 각 $\mathrm{IMC}$ 의 성장속도는 실험값에 선형보간법을 이용하여 구 한 직선의 기울기의 값을 확인하였을 때, $\mathrm{Cu}_{6} \mathrm{Sn}_{5}$ 는 $0.02425 \mu$ $\mathrm{m} / \mathrm{hr} \mathrm{Cu} \mathrm{Cu}_{3} \mathrm{Sn}$ 은 $0.00682 \mu \mathrm{m} / \mathrm{hr}$ 의 값을 나타내었다. 따라서 $\mathrm{Cu}_{3} \mathrm{Sn}$ 보다 $\mathrm{Cu}_{6} \mathrm{Sn}_{5}$ 의 성장속도가 더 빠름을 알 수 있었다.

그림 $5 \mathrm{~b}$ 는 $1.9 \times 10^{4} \mathrm{~A} / \mathrm{cm}^{2}$ 의 전류밀도에서 시간에 따른 $\mathrm{IMC}$ 의 두께를 측정한 결과이다. $\mathrm{Cu}_{3} \mathrm{Sn}$ 의 두께는 electromigration 시험 전 $0.33 \mu \mathrm{m}$ 에서 300시간 후 $7.17 \mu \mathrm{m}$ 로 증가하였다. 또한 $\mathrm{Cu}_{6} \mathrm{Sn}_{5}$ 의 두께는 electromigration 시험 전 $1.20 \mu \mathrm{m}$ 에서 300 시간 후 $17.16 \mu \mathrm{m}$ 로 증가하였다. $\mathrm{Cu}_{3} \mathrm{Sn}$ 과 $\mathrm{Cu}_{6} \mathrm{Sn}_{5}$ 는 모두 시간이 지나면서 성장하였지만, 선형보간법 에 의한 $\mathrm{Cu}_{6} \mathrm{Sn}_{5}$ 의 피팅(fitting) 직선 기울기는 $0.04777 \mu \mathrm{m} / \mathrm{hr}$ 로 $\mathrm{Cu}_{3} \mathrm{Sn}$ 의 $0.02125 \mu \mathrm{m} / \mathrm{hr}$ 보다 크게 측정되었다. 따라서 1.3 $\times 10^{4} \mathrm{~A} / \mathrm{cm}^{2}$ 의 전류밀도에서와 같이, $1.9 \times 10^{4} \mathrm{~A} / \mathrm{cm}^{2}$ 의 전류 밀도 인가 시에도 $\mathrm{Cu}_{6} \mathrm{Sn}_{5}$ 가 $\mathrm{Cu}_{3} \mathrm{Sn}$ 보다 더 빨리 성장함을 알 수 있었다.

전류밀도 $1.3 \times 10^{4} \mathrm{~A} / \mathrm{cm}^{2}$ 와 $1.9 \times 10^{4} \mathrm{~A} / \mathrm{cm}^{2}$ 에서의 IMC 두께 실험 결과를 비교하였을 때, 높은 전류밀도 $1.9 \times 10^{4}$
$\mathrm{A} / \mathrm{cm}^{2}$ 에서 $\mathrm{Cu}_{3} \mathrm{Sn}$ 성장속도는 약 3 배, $\mathrm{Cu}_{6} \mathrm{Sn}_{5}$ 는 약 2 배 빨랐 다. 전류밀도의 크기가 $1.3 \times 10^{4} \mathrm{~A} / \mathrm{cm}^{2}$ 에서 $1.9 \times 10^{4} \mathrm{~A} / \mathrm{cm}^{2}$ 로 1.5 배 증가한 것에 비해 $\mathrm{IMC}$ 의 두께는 2-3배 증가하였다.

\section{2 모델링 변수 설정}

$\mathrm{Cu}$ 와 $\mathrm{Sn}$ 의 유효전하수(effective charge number)는 기존 진행된 연구 결과 중 산포가 적고 높은 신뢰성을 가진 값을 적용하였다 [26-32]. 그러나 IMC에서의 유효전하수에 대한 연구는 시작 단계이므로 [28], 매우 큰 산포범위를 가지고 있 어서 모델링 변수값 선정에 어려움이 있었다. 따라서 $\mathrm{Cu}$ 와 $\mathrm{Sn}$ 에서의 유효전하수는 중간값을 선택하였으며, IMC에서의 유효전하수는 기존 발표된 유효전하수 값을 참조하되 식 (2) 와 (3)에 Newton-Raphson법으로 실험값을 활용하여 값을 선 정하였다 [32]. 솔더 리플로우 시 $\mathrm{Sn}$ 의 결정방위는 (001)면, (100)면과 (110)면이 임의로 배열된다고 알려져 있다 [33,34]. 따라서 리플로우 후 임의로 배열되는 결정방위를 고 려하여 확산계수는 기존의 문헌들에서 알려진 각 결정방위 값들의 중간값을 선택하였다. IMC 성장속도 모델링에 사용 한 모든 변수값은 표 2에 정리하였다.

\subsection{IMC 성장속도 모델링 및 실험결과 비교}

표 2에 주어진 변수값을 식 (7)과 (8)에 적용하여 electromigration에 의한 IMC 성장 두께 예측값을 계산하였 고, 이 예측값과 그림 5에 나타낸 실험값을 그림 6에 비교하 여 나타내었다. $\mathrm{Cu}_{3} \mathrm{Sn}$ 과 $\mathrm{Cu}_{6} \mathrm{Sn}_{5}$ 의 두께 실험값은 각각 파란 색과 붉은색 동그라미로 표기하였고, $\mathrm{Cu}_{3} \mathrm{Sn}$ 과 $\mathrm{Cu}_{6} \mathrm{Sn}_{5}$ 의 두 께 예측값은 각각 파란색과 붉은색 직선으로 표기하였다. 그 림 $6 \mathrm{a}$ 는 전류밀도 $1.3 \times 10^{4} \mathrm{~A} / \mathrm{cm}^{2}$ 에서 전류 인가 시간에 따 른 $\mathrm{IMC}$ 두께, 즉 $\mathrm{IMC}$ 의 성장속도를 나타낸다. $\mathrm{Cu}_{3} \mathrm{Sn}$ 두께의 
Table 2. Selected coefficient values of $\mathrm{Cu}, \mathrm{Sn}, \mathrm{Cu}_{3} \mathrm{Sn}$, and $\mathrm{Cu}_{6} \mathrm{Sn}_{5}$ in solder bump

\begin{tabular}{|c|c|c|c|}
\hline Parameter & Phase & \multicolumn{2}{|r|}{ Value } \\
\hline \multirow{4}{*}{$\begin{array}{c}\text { Resistivity } \\
(\Omega \cdot \mathrm{nm})\end{array}$} & $\mathrm{Cu}$ & \multicolumn{2}{|r|}{$16.8[35]$} \\
\hline & $\mathrm{Cu}_{3} \mathrm{Sn}$ & \multicolumn{2}{|r|}{89.3 [36] } \\
\hline & $\mathrm{Cu}_{6} \mathrm{Sn}_{5}$ & \multicolumn{2}{|r|}{$175[36]$} \\
\hline & $\mathrm{Sn}$ & \multicolumn{2}{|r|}{$115[35]$} \\
\hline \multirow{8}{*}{$\begin{array}{l}\text { Effective } \\
\text { charge } \\
\text { number }\end{array}$} & \multirow{2}{*}{$\mathrm{Cu}$} & $\mathrm{Cu}$ & $4.5[26-28]$ \\
\hline & & $\mathrm{Sn}$ & $2[30]$ \\
\hline & \multirow{2}{*}{$\mathrm{Cu}_{3} \mathrm{Sn}$} & $\mathrm{Cu}$ & 5 \\
\hline & & $\mathrm{Sn}$ & 15 \\
\hline & \multirow{2}{*}{$\mathrm{Cu}_{6} \mathrm{Sn}_{5}$} & $\mathrm{Cu}$ & 13 \\
\hline & & $\mathrm{Sn}$ & 12 \\
\hline & \multirow{2}{*}{$\mathrm{Sn}$} & $\mathrm{Cu}$ & $10[31]$ \\
\hline & & $\mathrm{Sn}$ & 18 [29] \\
\hline \multirow{8}{*}{$\begin{array}{c}\text { Diffusion } \\
\text { coefficient } \\
\left(\mathrm{m}^{2} / \mathrm{s}\right)\end{array}$} & \multirow{2}{*}{$\mathrm{Cu}$} & $\mathrm{Cu}$ & $1.24 \times 10^{-29}[31]$ \\
\hline & & $\mathrm{Sn}$ & $1.95 \times 10^{-23}[31]$ \\
\hline & \multirow{2}{*}{$\mathrm{Cu}_{3} \mathrm{Sn}$} & $\mathrm{Cu}$ & $2.11 \times 10^{-16}[31]$ \\
\hline & & $\mathrm{Sn}$ & $1.18 \times 10^{-16}[31]$ \\
\hline & \multirow{2}{*}{$\mathrm{Cu}_{6} \mathrm{Sn}_{5}$} & $\mathrm{Cu}$ & $1.25 \times 10^{-15}[31]$ \\
\hline & & $\mathrm{Sn}$ & $3.29 \times 10^{-16}[31]$ \\
\hline & \multirow{2}{*}{ Sn } & $\mathrm{Cu}$ & $2.01 \times 10^{-11}[31]$ \\
\hline & & $\mathrm{Sn}$ & $2.35 \times 10^{-15}[31]$ \\
\hline
\end{tabular}

예측값과 실험 측정값은 매우 근사한 값을 보였다. 반면 $\mathrm{Cu}_{6} \mathrm{Sn}_{5}$ 두께의 예측값은 실험값보다 큰 값을 보였지만, 전체 적으로 비슷한 거동을 모사하였다. 실험값 대비 예측값의 오 차는 최소 $2 \%$, 최대 $25 \%$ 발생하였다. 그림 $6 \mathrm{~b}$ 는 $1.9 \times 10^{4}$ $\mathrm{A} / \mathrm{cm}^{2}$ 의 전류밀도를 인가하였을 때 IMC 성장속도를 나타내

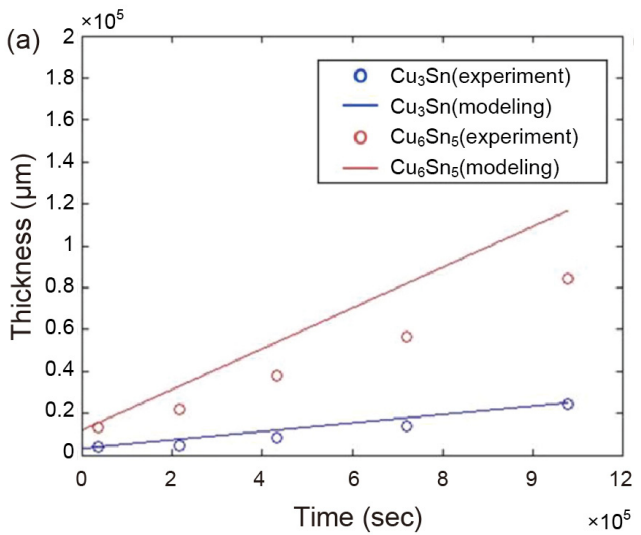

었으며, $1.3 \times 10^{4} \mathrm{~A} / \mathrm{cm}^{2}$ 의 결과와 동일하게 예측값과 실험값 은 유사한 거동을 보였다. 실험값과 예측값의 오차는 최소 $3 \%$, 최대 $30 \%$ 발생하였다.

실험값과 예측값의 오차는 전반적으로 낮은 전류밀도 1.3 $\times 10^{4} \mathrm{~A} / \mathrm{cm}^{2}$ 에서 작게 나타남을 확인하였다. 이는 Nernst-Einstein식 모델링에 의한 예측값이 electromigration 만을 고려한 결과이므로, 비교적 낮은 전류밀도 $1.3 \times 10^{4}$ $\mathrm{A} / \mathrm{cm}^{2}$ 에서 우수한 재현성을 보인 것으로 판단된다. 그러나 높은 전류밀도 $1.9 \times 10^{4} \mathrm{~A} / \mathrm{cm}^{2}$ 에서는 Joule 열에 의한 온도 상승효과가 커져서 electromigration에 의한 Nernst-Einstein 식으로 모델링을 할 경우 큰 오차값이 발생할 수 있음을 의미 한다. 본 연구의 결과는 이전 연구에서도 동일하게 보여지고 있다. Lee 등은 [37] electromigration에 의한 Sn-3.5Ag 솔더 범프 실험에서 전류밀도가 $6 \times 10^{4} \mathrm{~A} / \mathrm{cm}^{2}$ 에서 $9 \times 10^{4} \mathrm{~A} / \mathrm{cm}^{2}$ 으로 1.5 배 증가하였을 때, 솔더 범프의 단락이 약 25 배 빠른 시간에 일어남을 보고하였다. 이에 대한 영향으로 Joule 열에 의한 시효(aging)와 thermomigration의 영향이라고 하였다. Joule 열에 의한 시효 효과가 IMC 두께에 미치는 영향은 $\mathrm{Zhao}$ 의 $\mathrm{Cu} / \mathrm{Sn} / \mathrm{Cu}$ 배선(interconnect)와 $\mathrm{Sn}-3.5 \mathrm{Ag}$ 솔더 연구 [38]에서 발표되었듯이, $250{ }^{\circ} \mathrm{C}$ 에서 2시간 시효 시 $\mathrm{Cu}_{3} \mathrm{Sn}$ 은 $1.53 \mu \mathrm{m}, \mathrm{Cu}_{6} \mathrm{Sn}_{5}$ 는 $8.45 \mu \mathrm{m}$ 성장하고, $280{ }^{\circ} \mathrm{C}$ 에서 2 시간 aging 시 $\mathrm{Cu}_{3} \mathrm{Sn}$ 은 $2.34 \mu \mathrm{m}, \mathrm{Cu}_{6} \mathrm{Sn}_{5}$ 는 $10.17 \mu \mathrm{m}$ 성장한다. 본 연구는 기존 Zhao의 연구보다 낮은 온도인 $150{ }^{\circ} \mathrm{C}$ 에서 300 시간까지 진행하였기 때문에, 시효의 power law $\left(\mathrm{h}=\mathrm{Kt}^{\mathrm{n}}, \mathrm{h}=\right.$ $\mathrm{IMC}$ 의 두께, $\mathrm{K}=\mathrm{IMC}$ 성장 속도 변수, $\mathrm{t}=$ 시간, $\mathrm{n}=$ 시간 지 수)에서 장시간의 실험 영향으로 상당한 IMC의 두께 변화를 예상할 수 있다. 그림 5 에서 전류밀도의 크기가 $1.3 \times 10^{4}$ $\mathrm{A} / \mathrm{cm}^{2}$ 에서 $1.9 \times 10^{4} \mathrm{~A} / \mathrm{cm}^{2}$ 로 1.5 배 증가할 때 $\mathrm{IMC}$ 의 두께는

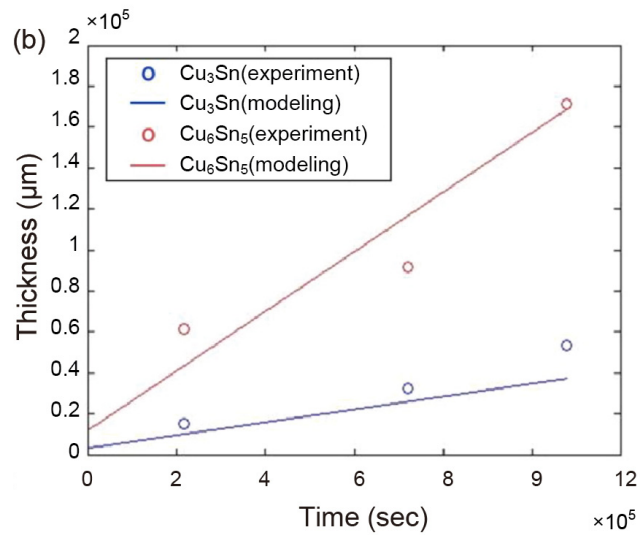

Fig. 6. Comparison of IMC growth modeling and experiment during electromigration for specific current density: (a) $1.3 \times 10^{4} \mathrm{~A} / \mathrm{cm}^{2}$ and (b) $1.9 \times 10^{4} \mathrm{~A} / \mathrm{cm}^{2}$. 
2-3배 증가한 것도, 전류가 증가함에 따라 electromigration뿐 만 아니라 Joule 열 효과에 의한 thermomigration 영향과 시 효의 영향 때문으로 판단된다.

다른 오차의 발생원인으로 $\mathrm{Sn}$ 의 결정방위 영향을 들 수 있 다. $\mathrm{Sn}$ 은 체심정방격자(body centered tetragonal, $\mathrm{BCT}$ ) 구조 로 (100)면과 (001)면에서 각각 다른 확산 계수 값을 가지고 있으며, 각 결정방위에서 $\mathrm{Sn}$ 의 확산계수는 $1.17 \times 10^{-16}, 4.59$ $\times 10^{-15} \mathrm{~m}^{2} / \mathrm{s}$ 로 (001)면이 (100)면에 비해 약 39배 높은 확산계 수를 가진다고 알려져 있다 [39]. 확산계수는 식 (2)에서 확인 할 수 있듯이 IMC 유속과 비례한다는 것을 알 수 있다. Huang 등은 [40] Sn-3Ag-0.5Cu 솔더 $\mathrm{Sn}$ 의 결정방위에 따른 electromigration 실험을 진행하였는데, (001)면이 (100)면에 비해 약 100 배 빠른 확산유속을 가진다고 발표하였다. 따라 서 본 실험에서 임의의 $\mathrm{Sn}$ 결정방위도 하나의 원인이 될 수 있다고 판단된다.

또한 웨이퍼와 기판을 연결시켜주는 솔더 접합부의 구조 때문에 실험값과 예측값의 오차가 발생할 수 있을 것으로 판 단된다. 그림 3에서 알 수 있듯이 웨이퍼의 $\mathrm{Cu}$ 패드는 솔더범 프에 3면이 노출되어 있어서, 솔더 계면에서의 IMC는 3 방향 으로 동시에 성장할 수 있다. 그러나 미세한 솔더범프의 크기 때문에 정렬이 일정하지 못할 경우, 그림 4에서와 같이 $\mathrm{Cu}$ 패 드는 솔더범프에 2면이 노출되는 경우도 발생한다. IMC 측 정은 $\mathrm{Cu}$ 패드에서 성장하는 $\mathrm{Cu}_{3} \mathrm{Sn}$ 과 $\mathrm{Cu}_{6} \mathrm{Sn}_{5}$ 을 관찰하므로 초기 솔더범프에 노출된 $\mathrm{Cu}$ 패드의 면 개수는 $\mathrm{IMC}$ 성장속도 에 영향을 줄 수 있다. 그리고 $\mathrm{Cu}$ 패드의 노출면 개수와 함께 전류의 직진성 때문에 실험값과 예측값에 오차가 발생할 수 있다. 전류는 그림 3 의 위쪽에 있는 웨이퍼에서 아래쪽의 기 판 방향으로 직진하려는 경향이 강하지만, $\mathrm{Cu}$ 패드가 노출되 어 있는 면의 수가 다수가 되면 전류의 흐름도 분산되므로 $\mathrm{IMC}$ 성장거동에 영향을 미치기 때문이다.

전반적으로 Nernst-Einstein식은 $\mathrm{Sn}-0.7 \mathrm{Cu}$ 솔더에서 electromigration에 의한 IMC 성장 예측이 가능함을 보였다. 특히 낮은 전류밀도 $1.3 \times 10^{4} \mathrm{~A} / \mathrm{cm}^{2}$ 와 구리 패드에 밀접하여 성장하는 $\mathrm{Cu}_{3} \mathrm{Sn}$ 두께는 실험값 대비 우수한 정확성을 보였 다. 그러나 높은 전류밀도 $\left(1.9 \times 10^{4} \mathrm{~A} / \mathrm{cm}^{2}\right)$ 와 구리 패드에서 떨어진 $\mathrm{Cu}_{6} \mathrm{Sn}_{5}$ 두께는 예측값과 실험값의 경향은 유사하였 지만, 정량적 값의 오차는 최대 $30 \%$ 까지 발생하였다. 본 연 구를 통하여 전류밀도가 $1.9 \times 10^{4} \mathrm{~A} / \mathrm{cm}^{2}$ 로 높아지면 IMC 성 장과 관련된 현상에서 electromigration 이외에도 Joule 열 효 과에 의한 aging과 theromigration 효과를 고려해야 함을 알 수 있었다. 또한 성장속도가 빠른 $\mathrm{Cu}_{6} \mathrm{Sn}_{5} \mathrm{IMC}$ 의 실험 오차를
줄이기 위하여 구리 패드가 솔더범프에 노출되는 면을 1 개로 고정시키고, 전류가 구리 패드를 지나면서 Joule 열이 발생하 지 않도록 구리 패드와 솔더범프의 직경이 동일하도록 막대 시편 형상으로 설계를 하는 것이 필요하다고 생각된다.

\section{5. 결 론}

본 연구는 직경 $100 \mu \mathrm{m}$ 의 $\mathrm{Sn}-0.7 \mathrm{Cu}$ 솔더범프에 전류 1-1.5 $\mathrm{A}$ (전류밀도 1.3-1.9 $\times 10^{4} \mathrm{~A} / \mathrm{cm}^{2}$ )를 인가하였을 때, electromigration에 의한 $\mathrm{IMC}$ 의 성장거동을 모델링 후 실험 값과 비교하여 다음과 같은 결론을 얻었다.

1. 전류밀도 $1.3 \times 10^{4} \mathrm{~A} / \mathrm{cm}^{2}$ 와 $1.9 \times 10^{4} \mathrm{~A} / \mathrm{cm}^{2}$ 를 인가하 였을 때, $\mathrm{Cu}_{3} \mathrm{Sn}$ 과 $\mathrm{Cu}_{6} \mathrm{Sn}_{5} \mathrm{IMC}$ 는 시간이 경과함에 따라 성장 하였다. 전류밀도가 $1.3 \times 10^{4} \mathrm{~A} / \mathrm{cm}^{2}$ 에서 $1.9 \times 10^{4} \mathrm{~A} / \mathrm{cm}^{2}$ 로 증가하였을 때, $\mathrm{IMC}$ 는 전류밀도의 증가율인 1.5 배보다 높은 2-3배 증가하였다.

2. Electromigation에 의한 각 $\mathrm{IMC}$ 의 성장속도는 $1.3 \times 10^{4}$ $\mathrm{A} / \mathrm{cm}^{2}$ 의 전류밀도에서 $\mathrm{Cu}_{6} \mathrm{Sn}_{5}$ 는 $0.02425 \mu \mathrm{m} / \mathrm{hr} \mathrm{Cu}_{3} \mathrm{Sn}$ 은 $0.00682 \mu \mathrm{m} / \mathrm{hr}$ 으로 측정되었고, 전류밀도를 $1.9 \times 10^{4} \mathrm{~A} / \mathrm{cm}^{2}$ 로 높이면 $\mathrm{Cu}_{6} \mathrm{Sn}_{5}$ 는 $0.04777 \mu \mathrm{m} / \mathrm{hr} \mathrm{Cu}_{3} \mathrm{Sn}$ 은 $0.02125 \mu \mathrm{m} / \mathrm{hr}$ 으로 측정되었다. 본 연구에서 수행한 전류밀도의 범위에서 는 모두 $\mathrm{Cu}_{3} \mathrm{Sn}$ 보다 $\mathrm{Cu}_{6} \mathrm{Sn}_{5}$ 의 성장속도가 빨랐다.

3. 실험값과 Nernst-Einstein식을 이용한 모델링 예측값을 비교하면, 전류밀도 $1.3 \times 10^{4} \mathrm{~A} / \mathrm{cm}^{2}$ 와 $1.9 \times 10^{4} \mathrm{~A} / \mathrm{cm}^{2}$ 에서 모두 IMC 성장 거동을 유사하게 모사하였다. IMC 성장속도 의 예측값이 실험값과 비슷하게 재현됨을 알 수 있었다. 특히 낮은 전류밀도 $1.3 \times 10^{4} \mathrm{~A} / \mathrm{cm}^{2}$ 와 $\mathrm{Cu}$ 패드에 밀접하여 성장 하는 $\mathrm{Cu}_{3} \mathrm{Sn}$ 두께는 실험값 대비 우수한 정확성을 보였다.

4. 높은 전류밀도 $\left(1.9 \times 10^{4} \mathrm{~A} / \mathrm{cm}^{2}\right)$ 와 $\mathrm{Cu}$ 패드에서 떨어진 $\mathrm{Cu}_{6} \mathrm{Sn}_{5}$ 두께는 예측값과 실험값의 경향은 유사하였지만, 정 량적 값의 오차는 최대 $30 \%$ 까지 발생하였다. 전류밀도가 1.9 $\times 10^{4} \mathrm{~A} / \mathrm{cm}^{2}$ 로 높아지면 $\mathrm{IMC}$ 성장과 관련된 현상에서 electromigration 이외에도 Joule 열 효과에 의한 시효와 theromigration 효과, 리플로우 후 솔더범프에서 $\mathrm{Sn}$ 의 결정방 위를 고려할 필요가 있음을 알 수 있었다.

\section{감사의 글}

이 논문은 산업통상자원부 산업융합원천기술개발사업의 지원과 2011년도 정부(미래창조과학부)의 재원으로 한국연 구재단의 지원을 받아 수행된 연구임(No. 2011-0030013). 


\section{REFERENCES}

1. J. H. Bang and C. W. Lee, Journal of KWJS 29, 593 (2011).

2. S. H. Chae, X. Zhang, K. H. Lu, H. L. Chao, P. S. Ho, M. Ding, P. Su, T. Uehling, and L. N. Ramanathan, J. Mater. Sci: Mater. Electron. 18, 247 (2007).

3. I. -Y. Lee, C. -B. Lee, S. -B. Jung and C. -C. Shur, Journal of KWS 20, 97 (2002).

4. S. H. Kim, H. K. Shin, C. M. Park, D. U. Kim, P. R. Cha, U. H. Lee and H. J. Lee, Korean J. Met. Mater. 53, 495 (2015).

5. S. H. Kim, B. R. Lee, G. T. Park, J. M. Kim, S. H. Yoo and Y. B. Park, Korean J. Met. Mater. 53, 735 (2015).

6. S. Brandenbery and S. Yeh, Proceeding Surface Mount International Conference and Exposition, p.337, SMTA, San jose, California (1998).

7. E. C. C. Yeh, W. J. Choi, N. Tu, P. Elenius and H. Balkan, Appl. Phys. Lett. 80, 580. (2002).

8. K. Zeng, R. Stierman, Tz. -C. Chiu, D. Edwards, K. Ano and K. N. Tu, J. Appl. Phys. 97, 024508 (2005).

9. R. Putnam, Am. Ind. Hyg. Assoc. 47, 700 (1986).

10. A. T. Huang, K. N. Tu and Y. -S. Lai, J. Appl. Phys. 100, 033512 (2006).

11. H. Ye, C. Basaran, and D. Hokins, Appl. Phys. Lett, 82, 1045 (2003).

12. T. Y. Lee, K. N. Tu, S. M. Kuo and D. R. Frear, J. Appl. Phys. 89, 3189 (2001).

13. A. S. M. A. Haseeb, M. M. Arafat and M. R. Johan, Mater. Charact. 64, 27 (2012).

14. T. -C. Chiu and K. -L. Lin and, Intermetallics 17, 1105 (2009).

15. G. -C. XU, F. Guo and W. -R. Zhu, Int. J. MIN. MET. MATER. 16, 685 (2009).

16. T. -C. Chiu and K. -L. Lin, Intermetallics 23, 208 (2012).

17. K. Yamanaka, Y. Tsukada and K. Suganuma, Microelectron. Reliab. 47, 1280 (2007).

18. R. Darveaux and K. Banerji, IEEE Trans. Compon. Hybirds. Manuf. Technol. 15, 1013 (1992).

19. K. N. Tu, Acta Metall. Mater. 21, 347 (1973).

20. H. I. Jeon, M. S. Thesis, pp.6-7, Pusan National University, Busan (2013).
21. G. Digiacomo, Reliability of electronic packages and semiconductor devices, 1st ed., pp.3.1-58, Mcgraw-hill, New York (1996).

22. D. M. Jacobson and G. Humpston, Solder. Surf. Mt. Tech. 4, 27 (1992).

23. N. Saunders and A. P. Miodownik, Bulletin of Alloy Phase Diagrams 11, 278, (1990).

24. M. Ding, Ph. D. Thesis, pp. 2-6, The University of Texas at Austin, Texas (2007).

25. O. M. Abdelhadi and L. Ladani, J. Alloy. Compd. 537, 87 (2012).

26. A. R. Grone, J. Phys. Chem. Solids 20, 88 (1961).

27. G. A. Sullivan, J. Phys. Chem. Solids 28, 347 (1967).

28. C. C. Wei, C. F. Chen, P. C. Liu and C. Chen, J. Appl. Phys. 105, 023715 (2009).

29. A. Khosla and H. B. Huntington, J. Phys. Chem. Solids 36, 395 (1975).

30. D. Grimme, Atomic transport in solids and liquids, pp.19, Verlag der Zeitschrift für Naturforschung, Tübingen (1971).

31. M. Y. Hsieh and H. B. Huntington, J. Phys. Chem. Solids 39, 867 (1978).

32. S. C. Chapra, Applied numerical Methods with MATLAB, pp.310-315, McGraw-Hill Korea, Seoul (2009).

33. A. Tasooji, L, Lara and K. Lee, J. Elctron. Mater. 43, 4386 (2014).

34. C. E. Ho, P. T. Lee, C. N. Chen and C. H. Yang, J. Alloy. Compd. 676, 361 (2016).

35. B. Chao, S. -H. Chae, X. Zhang, K. -H. Lu, J. Im and P. S. Ho, Acta Mater. 55, 2805 (2007).

36. P. -C. Yang, C. -C. Kuo and C. Chen, JOM-US 60, 77 (2008).

37. J. H. Lee, G. T. Lim, Y. B. Park, S. T. Yang, M. S. Suh, Q. H. Chung and K. Y. Byun, J. Korean Phys. Soc. 54, 1784 (2009).

38. N. Zhao, Y. Zhong, M. L. Huang, H. T. Ma and W. Dong, Sci. Rep. 5, 13491 (2015).

39. N. L. Peterson, Solder state physics, 22th ed, pp.409-512, Academic Press, New York (1969).

40. M. L. Huang, J. F. Zhao, Z. J. Zhang and N. Zhao, J. Alloy. Compd. 678, 370 (2016). 